\title{
Clinical Features, Prognosis, Diagnostic Approaches and Treatment of Multiple Primary Malignancies in the Digestive System
}

\author{
AKASHI IKUBO ${ }^{1}$, SHOHEI MATSUFUJI ${ }^{1}$, YOSHIHIRO MORIFUJI ${ }^{2}$, HIROKI KOGA $^{1}$, \\ TOMONARI KOBARAI ${ }^{3}$, NAOHIKO KOUYA ${ }^{1}$, MASASHI SAKAI ${ }^{1}$, RYUICHIROU SAMEJIMA $^{1}$, \\ KATSUO KOJIMA ${ }^{2}$, MASANOBU TABUCHI ${ }^{3}$ and SEIJI YUNOTANI ${ }^{1}$ \\ ${ }^{I}$ Department of Surgery, Japanese Red Cross Karatsu Hospital, Saga, Japan; \\ ${ }^{2}$ Department of Thoracic Surgery, Japanese Red Cross Karatsu Hospital, Saga, Japan; \\ ${ }^{3}$ Department of Breast Surgery, Japanese Red Cross Karatsu Hospital, Saga, Japan
}

\begin{abstract}
Background/Aim: Additional primary malignancy $(A P M)$ risk is increasing with improved prognosis of cancer survivors. In order to clarify risk factors and patients susceptible to develop APMs, we investigated the clinical features, prognosis, and approaches for diagnosis and treatment in these patients. Patients and Methods: Among 874 patients newly diagnosed with gastrointestinal tract (GIT) or hepato-biliary-pancreatic (HBP) cancers between 2011 and 2014, 124 with a synchronous and/or metachronous APM were identified. Patient characteristics, time interval between the malignancies, clue to detect APMs, treatment approaches, and prognosis were investigated. Results: Patients with APMs were older and predominantly male. Half of the metachronous APMs were detected within 3 years after the first primary malignancy $(P M)$. The main clue to detect synchronous and metachronous APMs was preoperative screening for current $P M$, and follow-up of prior $P M$, respectively. There was no significant difference in the overall survival between colon cancer patients with or without APMs. Conclusion: Multiple PMs were present in $14.2 \%$ of patients. Male and old age were identified to be risk factors for APM. Pre-operative screening and post-operative regular follow-ups are important for detecting synchronous or metachronous APMs.
\end{abstract}

We presented part of this article at the 71th general meeting of the Japanese Society of Gastroenterological Surgery in 2016.

Correspondence to: Akashi Ikubo: Department of Surgery, Japanese Red Cross Karatsu Hospital, 2430 Watada, Karatsu-shi, Saga $847-$ 8588, Japan. Tel: +81 955725111, Fax: +81 955739530, e-mail: akashi-ikubo@karatsu.jrc.or.jp

Key Words: Additional primary malignancy (APM), digestive system, colon cancer, hepatobiliary-pancreatic cancer.
Increased prevalence of cancer screening approaches and advances in diagnostic methods, surgical procedures, anticancer drugs, and molecular-targeted agents have increased the life expectancy of cancer survivors, increasing additional primary malignancy (APM) risk. In Japan, second primary malignancies (PMs) are often investigated among juvenile cancer survivors because multidisciplinary therapy has improved the cure rate, including that of lymphoblastic lymphoma, to $>80 \%$ (1); however, the risk of subsequent life-threatening secondary cancers is also increased (1-3). Examination of the characteristics of patients with APM is necessary to identify risk factors and patients at risk of developing APMs. Several studies on multiple PMs have reported the incidence rate or APM sites (4-7); however, diagnostic approaches and prognosis of these cases have not been completely described $(4,5)$. Therefore, we investigated patients with newly diagnosed gastrointestinal tract (GIT) and hepato-biliary-pancreatic (HBP) cancers who had synchronous or metachronous APMs to elucidate the clinical features, prognosis, and approaches for diagnosis and treatment of these patients.

\section{Patients and Methods}

Of the 874 patients with newly diagnosed GIT and HBP cancers between January 2011 and December 2014 at our hospital, 124 who had synchronous and/or metachronous APMs through May 2016 were included in the analysis. Multiple malignancies were defined based on the criteria described by Warren and Gate (8).

Patients with malignancies in the same organ and autopsy cases were excluded. The "current" PM was defined as a newly diagnosed malignancy between 2011 and 2014. In patients who did not undergo surgery and those with no histological specimens available, malignancy was diagnosed based on imaging methods (ultrasonography, computed tomography, or magnetic resonance imaging) and tumor markers specific for the affected organ. 
Table I. Patient characteristics and APM ratios.

\begin{tabular}{|c|c|c|c|c|c|c|c|c|c|c|}
\hline \multirow[b]{2}{*}{ Current Site } & \multirow[b]{2}{*}{$\begin{array}{l}\text { Patient } \\
\text { number }\end{array}$} & \multicolumn{3}{|c|}{ Multiplicity } & \multirow[b]{2}{*}{$\begin{array}{c}\text { Patient } \\
\text { with APM }\end{array}$} & \multirow{2}{*}{$\begin{array}{c}\text { APM } \\
\text { Ratio } \\
(\%)\end{array}$} & \multicolumn{2}{|c|}{ Gender } & \multicolumn{2}{|c|}{ Age (median) } \\
\hline & & Double & Triple & Quadruple & & & $\begin{array}{c}\text { Multiple PMs } \\
\text { Male/Female }\end{array}$ & $\begin{array}{c}\text { Single PM } \\
\text { Male/Female }\end{array}$ & Multiple & Single \\
\hline Esophagus & 45 & 6 & 4 & 0 & 10 & 22.2 & $10 / 0(100.0)^{*}$ & $32 / 3(82.9)$ & 71.5 & 72.5 \\
\hline Stomach & 319 & 17 & 9 & 0 & 26 & 8.2 & $21 / 5(80.8)$ & $206 / 87(70.3)$ & 78 & 72.5 \\
\hline Colon & 237 & 43 & 6 & 1 & 50 & 21.1 & $30 / 20(60.0)$ & $88 / 99$ (47.1) & 76 & 74.5 \\
\hline Rectum & 95 & 10 & 2 & 1 & 13 & 13.7 & $10 / 3(76.9)$ & $55 / 27(67.1)$ & 74 & 70.5 \\
\hline Liver & 71 & 9 & 3 & 1 & 13 & 18.3 & $11 / 2(84.6)$ & $44 / 14(75.9)$ & 75 & 71.5 \\
\hline Bile duct & 26 & 2 & 0 & 0 & 2 & 7.7 & $2 / 0(100.0)$ & $11 / 13(45.8)$ & 80.5 & 80 \\
\hline Gallbladder & 18 & 2 & 1 & 0 & 3 & 16.7 & $3 / 0(100.0)$ & $3 / 12(20.0)$ & 75 & 80 \\
\hline Pancreas & 57 & 6 & 0 & 0 & 6 & 10.5 & $3 / 3(50.0)$ & $28 / 23(54.9)$ & 81 & 72 \\
\hline Duodenum $\#$ & 6 & 1 & 0 & 0 & 1 & 16.7 & $0 / 1(0)$ & $3 / 2(60.0)$ & 83 & 80 \\
\hline Total & 874 & 96 & 25 & 3 & 124 & 14.2 & $90 / 34(72.6)$ & $470 / 280(62.7)$ & & \\
\hline
\end{tabular}

\#Ampulla of Vater; ( )* Ratio of Male $\%$.

Malignancies were defined as synchronous if the elapsed time between the two PMs was $<6$ months, and as metachronous if the elapsed time between the two PMs was $\geq 6$ months, according to Moertel (9). Synchronous esophageal/gastric cancers $(n=4)$, detected at the same time during an endoscopic examination, were considered as double current cancers; the four patients were included in the esophagus and stomach cancer cohort. This was considered for all nine colon/rectum cancer patients synchronously diagnosed using endoscopy. GIT and HBP cancer stages were classified as early (stage 0 or I) or advanced ( $\geq$ stage II) according to the Japanese Classification of Carcinoma.

Overall survival (OS) of patients with colon cancer with or without APMs was compared for each cancer stage (I-III); those with stage 0 or IV colon cancer were excluded because there was no mortality among patients with stage 0 cancer, and there was only 1 patient with APM with stage IV cancer.

Kaplan-Meier method was used to evaluate OS. The rates between two groups were compared using the log-rank test. $p<0.05$ was considered significant. All statistical analyses were performed using the statistical software R (10).

\section{Results}

APM ratios and involved sites. Among 874 patients with GIT and HBP cancers, 124 (14.2\%) had multiple APMs, including $96(77.4 \%), 25(20.2 \%)$, and 3 (2.4\%) with two, three, and four PMs, respectively (Table I). In subgroup analysis, multiple PM ratios were high in patients with esophageal and colon cancers and low in those with stomach and bile duct cancers.

Distribution of APMs. Overall, the ratio of males with multiple PMs was $72.6 \%$, higher than that of males with a single PM (62.7\%) (Table I). All patients with esophageal, bile duct, or gallbladder cancer with APMs were males. Patients with APMs tended to be older than those with a single PM for each organ.
Sites of APMs. The most predominant site for APM was the stomach, followed by the colon and prostate (Table II). A similar trend was observed among the males with APMs; however, in females, the most predominant site for APM was the colon and breast, followed by the rectum, lungs and hematopoietic system. Regarding APM sites, 5 (83.3\%) and $7(50 \%)$ patients with hematopoietic malignancies and lung cancer, respectively, had current colon cancer. The most common site pairs for synchronous malignancies were esophagus-stomach $(\mathrm{n}=6,100 \%)$, followed by rectum-colon $(n=9,56.3 \%$; data not shown). The patients with current gastric and colon cancer had APMs in various sites.

Time interval between the first-current or currentsubsequent malignancies. Of the 148 multiple malignancies, $83(56.1 \%)$ were metachronous, of which 41 (49.4\%) were diagnosed within 3 years after the first malignancy (Table III). For current liver cancer with metachronous APMs, all patients had a diagnosis of prior malignancy, and the time elapsed between the two PMs was long (1->30 years); $>40 \%$ of these additional liver cancers were detected $>10$ years after the first PM (data not shown).

Clues to detect APMs. Of the 66 synchronous APMs, 62 (93.9\%) were diagnosed by pre-operative screening of the current PM (Table IV). Among the patients with metachronous APMs, most malignancies were detected during follow-up for the prior malignancy $(n=43,45.7 \%)$, followed by patient symptoms $(n=32,34.0 \%)$.

Current cancer stage and progression degree of the current and additional malignancies. Of 124 patients with multiple PMs, the current cancer stage was known in 110 (Table V). 
Stage IV cancer ratio was higher among patients with HBP cancer $(n=9,36 \%)$, especially those with pancreato-biliary cancer, compared to the patients with GIT cancer $(n=7$, $7.1 \%$ ). Of the 103 malignancy pairs of current and additional malignancies with available data on disease progression, the ratio of pairs with both advanced-stage malignancies was higher in synchronous pairs $(\mathrm{n}=23,40.4 \%)$ than in metachronous pairs $(\mathrm{n}=10,21.7 \%)$.

Treatment approaches for current and synchronous PMs. Surgery was the most common treatment approach for the current GIT and HBP cancers (Table VI). The ratio of surgery with curative intent was higher $(\mathrm{n}=68,63.6 \%)$ for GIT than for HBP $(n=12,44.4 \%)$ cancer. Conversely, the best supportive care ratio for current cancer was higher for HBP $(n=5,18.5 \%)$ than for GIT $(n=3,2.8 \%)$ cancer. Regarding synchronous APMs as well, surgery was the most common treatment, and simultaneous surgery was performed for $17(54.8 \%)$ lesions among 31 APM surgeries and for 2 (28.6\%) lesions among 7 APM surgeries with current GIT and HBP cancers, respectively.

Prognosis of patients with APMs. Thirty (24.2\%) among a total of 124 patients with APMs lived for $\geq 5$ years after the first malignancy (Figure 1). The ratio of patients who died during the 1st and between the 2nd and 3rd year was higher for synchronous APMs than for metachronous APMs (10.2\% vs. $1.3 \%, 30.6 \%$ vs. $5.3 \%$, respectively). Because the number of colon cancer cases with APMs was highest in this study $(n=50)$, we compared the OS of colon cancer patients with and without APMs for each stage (I-III) at the same period. There were no differences in OS between the two groups in each stage (log-rank test: $p=0.154,0.448$, and 0.103 , for stage I, II, and III, respectively; Figure 2).

\section{Discussion}

The results revealed that aged, male cancer survivors are at a higher risk for developing APMs, in agreement with previous studies (4, 5, 11-14). Smoking, environmental factors, and treatments for prior malignancies, including chemotherapy or radiotherapy, predispose patients to new PMs (6). Long-living cancer survivors harbor these risk factors; therefore, aging is another risk factor for APMs $(12,14)$.

Multiple PM ratios widely differed among the current PM sites, and sex differences were observed in the common sites of APMs. Reportedly, the ratio and most frequent sites of APM differ by era, country, first PM site, and patients' race and age $(5,13,14)$, as well as the analysis methods (15). A study from the USA found that approximately $25 \%$ of older ( $\geq 65$ years) and $11 \%$ of younger adults ( $<65$ years) had prior malignancies in a cohort of 740,990 cancer patients (7). Another study, including the period between 1973 and 2003, reported that the

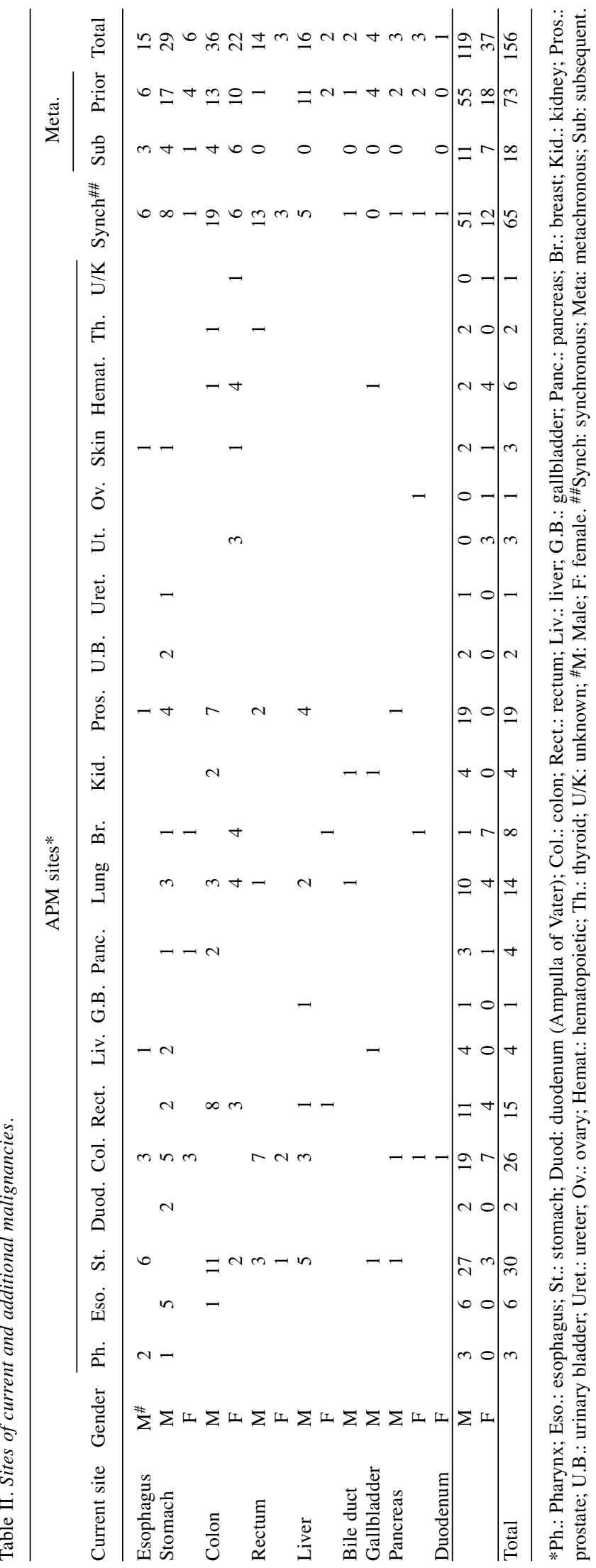


Table III. Time interval from 1st PM to current cancer/current cancer to next PM.

\begin{tabular}{|c|c|c|c|c|c|c|c|c|c|c|c|}
\hline \multirow[b]{2}{*}{ Current site } & \multicolumn{7}{|c|}{ Years between the two PMs } & \multicolumn{2}{|c|}{ Metachronous $(n=83)$} & \multirow[t]{2}{*}{ Synchronous } & \multirow[t]{2}{*}{ Total } \\
\hline & $<1 \mathrm{y}$ & $1-3 y$ & $3-5 y$ & $5-10 y$ & $10-15 y$ & $15-20 y$ & $20 \mathrm{y}-$ & Prior & Subsequent & & \\
\hline Esophagus & $0 / 1^{*}$ & $4 / 2$ & $1 / 0$ & & & $1 / 0$ & & 6 & 3 & 6 & 15 \\
\hline Stomach & $5 / 1$ & $3 / 3$ & $5 / 1$ & $2 / 0$ & $3 / 0$ & $1 / 0$ & & 19 & 5 & 9 & 33 \\
\hline Colon & $2 / 2$ & $9 / 5$ & $4 / 3$ & $4 / 0$ & $1 / 0$ & $1 / 0$ & & 21 & 10 & 25 & 56 \\
\hline Rectum & & & & & $1 / 0$ & & & 1 & 0 & 16 & 17 \\
\hline Liver & $1 / 0$ & $1 / 0$ & $1 / 0$ & $2 / 0$ & $2 / 0$ & & $2 / 0(20 y, 33 y)$ & 9 & 0 & 5 & 14 \\
\hline Bile duct & & & & $1 / 0$ & & & & 1 & 0 & 1 & 2 \\
\hline Gallbladder & & & & $2 / 0$ & $2 / 0$ & & & 4 & 0 & 0 & 4 \\
\hline Pancreas & & $2 / 0$ & $1 / 0$ & & & & $1 / 0(20 y)$ & 4 & 0 & 2 & 6 \\
\hline \multirow[t]{2}{*}{ Duodenum } & & & & & & & & 0 & 0 & 1 & 1 \\
\hline & $8 / 4$ & $19 / 10$ & $12 / 4$ & $11 / 0$ & $9 / 0$ & $3 / 0$ & $3 / 0$ & & & & \\
\hline Total & 12 & 29 & 16 & 11 & 9 & 3 & 3 & 65 & 18 & 65 & 148 \\
\hline
\end{tabular}

*first to current PM /current to subsequent PM.

Table IV. Clues to find APMs.

\begin{tabular}{|c|c|c|c|c|c|c|c|c|c|}
\hline \multirow[b]{2}{*}{ Current Site } & \multicolumn{5}{|c|}{ Clues } & \multicolumn{3}{|c|}{ Metachronous ( $\mathrm{n}=94)$} & \multirow[b]{2}{*}{$\begin{array}{c}\text { Synchronou } \\
\quad(n=66)\end{array}$} \\
\hline & Screening & Follow-up & Symptom & $\begin{array}{c}\text { Medical } \\
\text { examination }\end{array}$ & Unknown & Others & Prior & Subsequent & \\
\hline Esophagus & $6 / 0^{*}$ & $0 / 8$ & $0 / 1$ & $0 / 1$ & & & 6 & 4 & 6 \\
\hline Stomach & $9 / 0$ & $0 / 8$ & $1 / 8$ & $0 / 1$ & $0 / 10$ & & 22 & 5 & 10 \\
\hline Colon & $23 / 1$ & $0 / 14$ & $2 / 15$ & $0 / 2$ & $0 / 1$ & $0 / 1$ & 34 & 10 & 25 \\
\hline Rectum & $16 / 0$ & & $0 / 1$ & & & & 1 & 0 & 16 \\
\hline Liver & $4 / 0$ & $0 / 9$ & $0 / 2$ & & $0 / 2$ & $1 / 0$ & 13 & 0 & 5 \\
\hline Bile Duct & $1 / 0$ & $0 / 1$ & & & & & 1 & 0 & 1 \\
\hline Gallbladder & & $0 / 2$ & $0 / 2$ & & & & 4 & 0 & 0 \\
\hline Pancreas & $2 / 0$ & $0 / 1$ & $0 / 3$ & & & & 4 & 0 & 2 \\
\hline Duodenum & $1 / 0$ & & & & & & 0 & 0 & 1 \\
\hline Total & $62 / 1$ & $0 / 43$ & $3 / 32$ & $0 / 4$ & $0 / 13$ & $1 / 1$ & 75 & 19 & 66 \\
\hline
\end{tabular}

*Synchronous/Metachronous.

highest percentage of multiple PMs was $16 \%$ in patients with urinary bladder cancer and the lowest percentage was $1 \%$ in those with liver cancer (11). These studies analyzed a large nationwide dataset and have potentially counted the metastases of the first PM as second PMs (12). A single-center study in China reported a multiple PM rate of $1 \%$ in a cohort of 15,683 cancer patients (13) and reported that the most frequent site of multiple PMs was upper GIT in less-developed geographic regions of China and colorectum in developed countries other than China, suggesting that this difference is related to economic factors, including poor eating habits.

In this study, the most common synchronous malignancy pairs were observed among GIT lesions. The high ratio of synchronous gastric-esophageal cancer pair has been reported (13). This finding reflects the possibility that these malignancy pairs have been simultaneously detected during the same endoscopic examination. Another possible explanation is that the field carcinogenesis concept that explains the effects of carcinogenic exposure or genetic factors in closely located tissues or organs $(11,13,15)$ including oral cavity and pharynx, urinary bladder and kidney, or colon and rectal cancer (11).

High ratios of colon-lung and colon-hematopoietic malignancy pairs among females were observed in our study. Half of our patients, including all females, with primary lung cancer were colon cancer survivors. Lung cancer in females was detected during colon cancer follow-up, 14-35 months after the colon surgery. A high frequency of subsequent lung 
Table V. Stage of current malignancy. Progression degree of current malignancy and APM.

\begin{tabular}{|c|c|c|c|c|c|c|c|c|c|c|c|c|}
\hline \multirow[b]{3}{*}{ Current site } & & & & & & \multirow[b]{3}{*}{ Total } & \multicolumn{6}{|c|}{ Progression degree; current malignancy/APM } \\
\hline & \multicolumn{5}{|c|}{ Stage of current malignancy } & & \multicolumn{3}{|c|}{ Metachronous $(\mathrm{n}=46)$} & \multicolumn{3}{|c|}{ Synchronous $(\mathrm{n}=57)$} \\
\hline & 0 & I & II & III & IV & & Ear*/Ear & Adv/Ear & $\mathrm{Adv} / \mathrm{Adv}$ & Ear/Ear & Adv/Ear & $\mathrm{Adv} / \mathrm{Adv}$ \\
\hline Esophagus & 1 & 2 & 2 & & 1 & 6 & 2 & 2 & & 2 & 3 & 1 \\
\hline Stomach & & 20 & 2 & & 3 & 25 & 5 & 8 & & 2 & 6 & 1 \\
\hline Colon & 7 & 10 & 19 & 11 & 1 & 48 & 5 & 9 & 8 & & 11 & 11 \\
\hline Rectum & & 2 & 3 & 6 & 2 & 13 & & & & & 7 & 7 \\
\hline GIT Total & 8 & 34 & 26 & 17 & 7 & 92 & 12 & 19 & 8 & 4 & 27 & 20 \\
\hline Liver & & 4 & 4 & 1 & 2 & 11 & 2 & 1 & 2 & & 3 & 1 \\
\hline Bile duct & & & & & & & & 1 & & & & \\
\hline Gallbladder & & & & & 2 & 2 & & & & & & \\
\hline Pancreas & & & & & 4 & 4 & & 1 & & & & 1 \\
\hline Duodenum & & & & & 1 & 1 & & & & & & 1 \\
\hline HBP Total & 0 & 4 & 4 & 1 & 9 & 18 & 2 & 3 & 2 & 0 & 3 & 3 \\
\hline Total & 8 & 38 & 30 & 18 & 16 & 110 & 14 & 22 & 10 & 4 & 30 & 23 \\
\hline
\end{tabular}

*Ear: Early (stage 0 or I); Adv: advanced ( $\geq$ stage II).

Table VI. Treatment for current malignancy and synchronous APMs.

\begin{tabular}{|c|c|c|c|c|c|c|c|c|c|c|}
\hline Current site & Surg* & Chemo & $\operatorname{Rad}$ & EMR/ESD & EndTx & CRT & Others & $\begin{array}{l}\text { None } \\
\text { (BSC) }\end{array}$ & Total & $\begin{array}{c}\text { Simultaneous } \\
\text { surg on } \\
\text { synchchronous APMs }\end{array}$ \\
\hline Esophagus & $2 /(2)^{\#}$ & $3 /(1)$ & 2 & $4 /(2)$ & & 3 & & $1 /(1)$ & $15 /(6)$ & \\
\hline Stomach & $11 /(3)$ & $5 /(3)$ & $/(1)$ & $11 /(2)$ & & & /(1)TACE & $1 /(1)$ & $28 /(11)$ & \\
\hline Colon & $45 /(15)$ & $1 /(3)$ & $/(1)$ & $4 /(2)$ & $/(2)$ & & & $1 /(2)$ & $51 /(25)$ & $/(10)$ \\
\hline Rectum & $10 /(11)$ & $2 /(1)$ & & 1 & $/(2)$ & 0 & & $/(1)$ & $13 /(15)$ & $/(7)$ \\
\hline Total & $68 /(31)$ & $11 /(8)$ & $2 /(2)$ & $20 /(6)$ & $/(4)$ & 3 & $/(1)$ & $3 /(5)$ & $107 /(57)$ & $/(17)$ \\
\hline Liver & $9 /(4)$ & & & $/(1)$ & & & 3 (TACE) & 1 & $13 /(5)$ & $/(2)$ \\
\hline Bile duct & & 1 & & & & & 2 (stent) & 1 & 4 & \\
\hline Gallbladder & $3[2 * *]$ & & & & & & & & 3 & \\
\hline Pancreas & $2 /(1)$ & $2 /(2)$ & & & & & & 2 & $6 /(3)$ & \\
\hline Duodenum & & & & & & & & 1 & 1 & \\
\hline Total & $14[2 * *] /(7)$ & $3 /(2)$ & 0 & $/(1)$ & 0 & 0 & 5 & 5 & $27[2 * *] /(10)$ & $/(2)$ \\
\hline
\end{tabular}

*Surg: Surgery; Chemo: chemotherapy; Rad: radiation therapy; EMR/ESD: endoscopic mucosal resection/endoscopic submucosal dissection; EndTx: Endocrine therapy; CRT: chemo-radio therapy; TACE: transarterial chemo-embolization; BSC: best supportive care. ${ }^{\#}$ treatment on current malignancy/ (treatment on synchronous APMs); [**] non curative surgery on current malignancy.

cancer has been reported at an average of 3.5 years after colorectal cancer surgery (4). Donin et al. (12) reported that among colorectal cancer survivors, the most commonly diagnosed second PM was prostate cancer, followed by lung cancer. Hayat et al. (11) showed that colorectal cancer is associated with a significantly elevated risk of subsequent lung cancer in females but not in males. A certain degree of correlation may exist between colon cancer and subsequent lung cancer, especially in females; however, the underlying cause remains unclear. In our study, $>80 \%$ of patients with hematopoietic malignancies as APMs had colon cancer; $80 \%$ of them were female survivors of prior hematopoietic malignancies and $60 \%$ had received chemotherapy for the prior hematological malignancy. Patients with a history of non-Hodgkin lymphoma were reported to have the highest risk of developing a second cancer among the 10 most common 


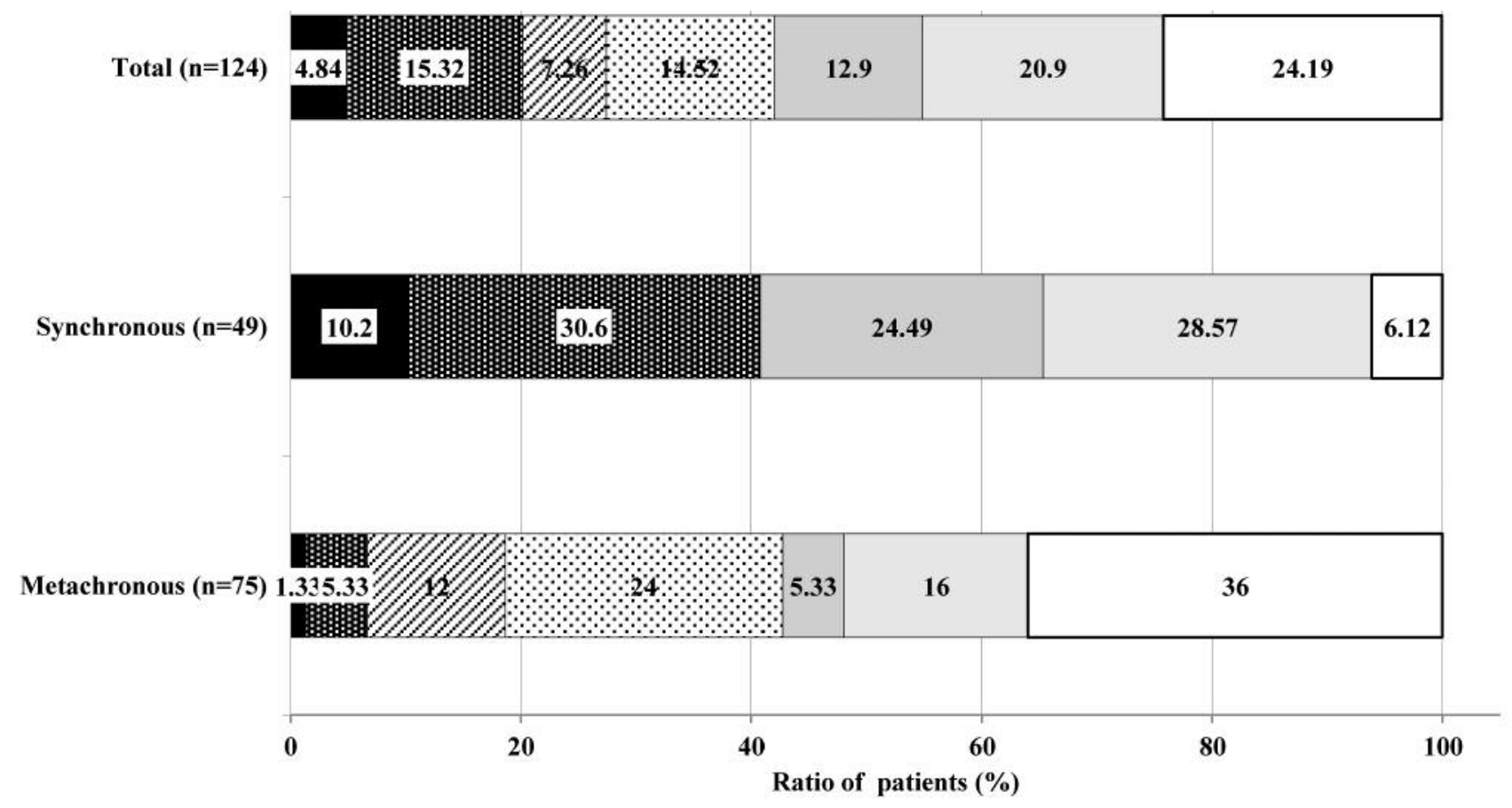

Figure 1. Prognosis of patients with additional primary malignancies (APMs). The time intervals from the first malignancy to the last day of followup or death are shown.

cancer sites, with the lungs being the most frequently second PM site, followed by prostate and colorectum (12). Although a history of prior hematopoietic malignancy might be a risk factor for subsequent colon cancer, especially for females, our study includes only epidemic results of a small cohort; therefore, further research on hematological malignancy with colon cancer is warranted to clarify this correlation.

The clues for the next malignancy diagnosis have not been extensively discussed in previous studies. In our study, $\geq 90 \%$ of synchronous APMs were found by pre-operative screening. Considering the high rate of synchronous PMs and field carcinogenesis, pre-operative screening is strongly recommended. Among patients with metachronous malignancies, almost half of them were detected during follow-ups for the prior cancer and $49.4 \%$ of APMs were diagnosed within 3 years (data now shown). Guan et al. (5) reported that, in colorectal cancer, the majority of secondary PMs are diagnosed within the first 60 months after the prior colorectal cancer diagnosis. Other studies have reported that the median time from the first gastric cancer to the first second PM ranges from 42 to 46.9 months $(15,16)$. Conversely, even 60 months after the prior colorectal cancer diagnosis, the risk of developing a second PM is high with some cancers, including small intestine, corpus uteri, and urinary bladder cancers (5), but not with liver cancer that was commonly diagnosed a long period after the prior PM, in our study. This discrepancy may be because of the higher rate of hepatitis virus infection in Japan than in the USA and European countries (17), which causes liver cancer several decades after the infection. In this study, among 13 patients with current liver cancer, 2 and 4 were positive for hepatitis $\mathrm{B}$ and $\mathrm{C}$ viruses, respectively, and 3 received transfusions, whereas 1 previously used illicit drugs, which are strong risk factors for hepatitis virus infection.

Previous studies have reported a shorter survival time for synchronous than for metachronous cancers (13-15). In this study, the ratio of two advanced-stage primary cancers and that of death within 3 years after the first malignancy diagnosis was higher for synchronous than for metachronous APM patients. The main clue to detect metachronous malignancies was prior cancer follow-up, which might facilitate the detection of the next APMs at an earlier stage, resulting in better prognosis (15).

Our results showed no significant difference between the OS of colon cancer patients with or without APMs; this finding is different from that of a previous series, reporting that the 
a Survival curve (stage I)

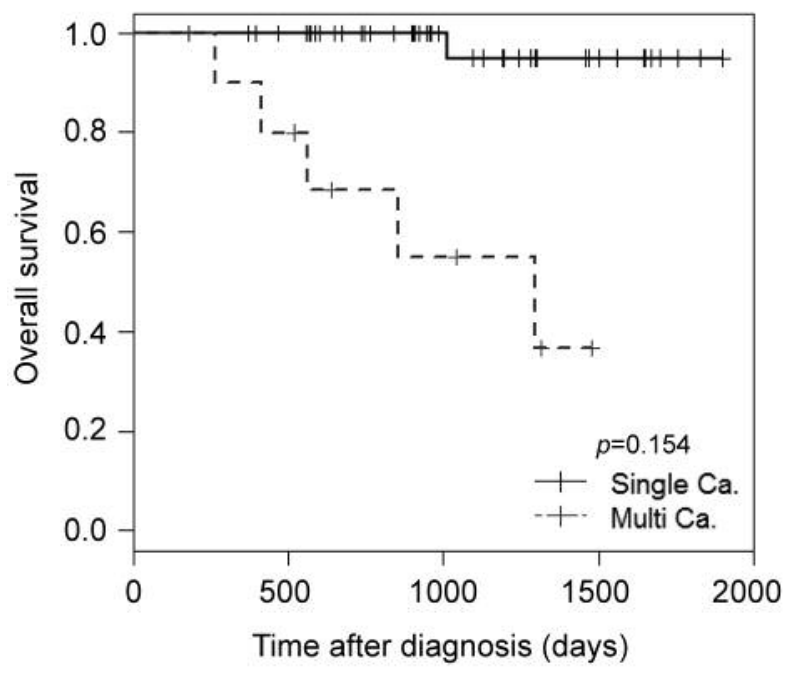

b Survival curve (stage II)

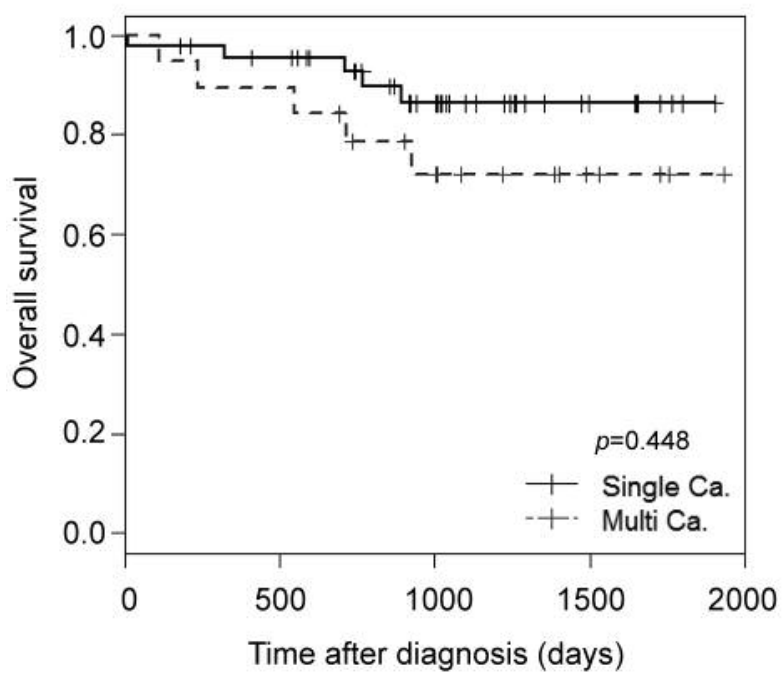

presence of double cancers is a poor prognostic factor in colon cancer (4) or that 5-year survival is lower after the second PM than after the same cancer occurring as first PM (18). One explanation for the conflicting findings might be the short follow-up duration and the small study cohort in this study.

One final consideration is the importance of patient interview in evaluating APMs. In the present cohort, one patient with three PMs was an atomic bomb survivor. Some patients with liver cancer had a history of transfusion or drug abuse. Although patients sometimes do not want to disclose their experiences, risk factors for APMs should be evaluated. Collecting data for analyzing larger patient cohorts with

\section{c Survival curve (stage III)}

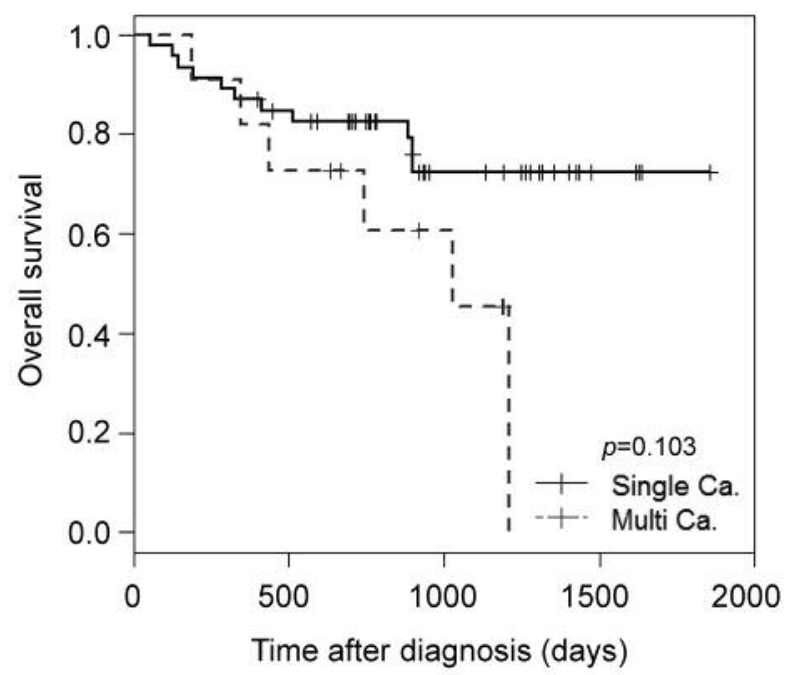

Figure 2. Overall survival of colon cancer patients with and without additional primary malignancies (APMs) in stages I-III. (a): stage I; (b): stage II; (c): stage III.

multiple PMs is necessary to identify additional risk factors and to improve prognosis, especially in patients with HBP cancer, diagnosis of whom at an operable stage is difficult.

This study has several limitations. The diagnosis was not based on pathology in all malignancies. Some malignancies were diagnosed at other hospitals a long time ago, and detailed records, including histological reports, could not be obtained for these cases. In other cases, even when the imaging and tumor marker studies strongly suggested a malignancy, no further histological examination was performed because of the patient's poor performance status, patient's refusal, or technical difficulties in obtaining samples, including those encountered in patients with pancreatic cancer. The study data lacked detail information on prior cancer treatments, including anticancer drugs and radiotherapy, health behaviors, familial history, and comorbidities, which might affect next malignancy development (18).

\section{Conclusion}

Old age, male sex, and esophageal and colon cancers are considered as risk factors for multiple cancers. Hematopoietic and colon cancers in females might aid in detecting future PM of the colon and lung, respectively. In real-world cancer practice, routine screening for the first malignant lesion is the key to detect a synchronous APM, and careful periodical follow-up for prior malignancy for at least 5 years aids in next PM detection. Finally, prognosis of colon cancer in patients with multiple PMs is not poor. 


\section{Conflicts of Interest}

All Authors declare no conflicts of interest related to our manuscript.

\section{Authors' Contributions}

AI designed the study, analyzed and interpreted the data, wrote the initial draft and revised the manuscript. All other Authors assisted in the preparation of the manuscript. All Authors approved the final version of the manuscript.

\section{References}

1 Sunami S, Sekimizu M, Takimoto T, Mori T, Mitsui T, Fukano R, Saito AM, Watanabe T, Ohsima K, Fujimoto J, Nakazawa A, Kobayashi R, Horibe K and Tsurusawa M: Prognostic impact of intensified maintenance therapy on children with advanced lymphoblastic lymphoma; a report from the Japanese pediatric leukemia/lymphoma study group ALB-NHL03 Study. Pediatr Blood Cancer 63(3): 451-457, 2015. PMID: 26585702. DOI: $10.1002 / p b c .25824$

2 Ishida Y, Maeda M, Adachi S, Inada H, Kawaguchi H, Hori H, Ogawa A, Kudo K, Kiyotani C, Shicino H, Rikiishi T, Kobayashi R, Sato M, Okamura J, Goto H, Manabe A, Yoshinaga S, Qiu D, Fujimoto J and Kuroda T: Secondary cancers after a childhood cancer diagnosis: viewpoints considering primary cancer. Int J Clin Oncol 23: 1178-1188, 2018. PMID: 29869758. DOI: 10.1007/s10147-018-1303-6

3 Ishida Y, Qui D, Maeda M, Fujimoto J, Kigasawa H, Kobayashi R, Sato M, Okamura J, Yoshinaga S, Rikiishi T, Shichino H, Kiyotani C, Kudo K, Asami K, Hori H, Kawaguchi H, Inada H, Adachi S, Mabnabe A and Kuroda T: Secondary cancers after a childhood cancer diagnosis: a nationwide hospital-based retrospective cohort study in Japan. Int J Clin Oncol 21: 506516, 2016. PMID: 26620038. DOI: 10.1007/s10147-015-0927-z

4 Shiozawa M, Tsuchida K, Sugano N, Morinaga S, Akaike M and Sugimasa Y: A clinical study of colorectal cancer with other primary cancer. Jpn J Gastroenterol Surg 40(9): 1557-1564, 2007. DOI: $10.5833 /$ jjgs.40.1557

5 Guan X, Jin Y, Chen Y, Jiang Z, Liu Z, Zhao Z, Yan P, Wang G and Wang $X$ : The incidence characteristics of second primary malignancy after diagnosis of primary colon and rectal cancer: A population-based study. PLoS One 10(11): e0143067, 2015. PMID: 26571301. DOI: 10.1371/journal.pone.0143067

6 Ławniczak M, Gawin A, Jaroszewicz-Heigelmann H, RogozaMateja W, Raszeja-Wyszomirska J, Białek A, KarpińskaKaczmarczyk $K$ and Starzyńska T: Synchronous and metachronous neoplasms in gastric cancer patients: a 23-year study. World J Gastroenterol 20(23): 7480-7487, 2014. PMID: 24966619. DOI: 10.3748/wjg.v20.i23.7480

7 Murphy CC, Gerber DE and Pruitt SL: Prevalence of prior cancer among persons newly diagnosed with cancer: An initial report from the Surveillance, Epidemiology, and End Results program. JAMA Oncol 4(6): 832-836, 2018. PMID: 29167866. DOI: $10.1001 /$ jamaoncol.2017.3605
8 Warren S and Gates O: Multiple primary, malignant tumors: a survey of the literature and statistical study. Am J Cancer 16: 1358-1414, 1932.

9 Moertel CG: Multiple primary malignant neoplasms: historical perspectives. Cancer 40: 1786-1792, 1977. PMID: 332330. DOI: 10.1002/1097-0142(197710)40:4+<1786::aid-cncr2820400803> 3.0.co; $2-2$

10 A language and environment for statistical computing; $\mathrm{R}$ Foundation for Statistical Computing, Vienna, Austria. Available at: https://www.R-project.org/

11 Hayat MJ, Howlader N, Reichman ME and Edwards BK: Cancer Statistics, Trends, and multiple primary cancer analyses from the Surveillance, Epidemiology, and End Results (SEER) program. Oncologist 12(1): 20-37, 2007. PMID: 17227898. DOI: 10.1634/theoncologist.12-1-20

12 Donin N, Filson C, Drakaki A, Tan HJ, Castillo A, Kwan L, Litwin $\mathrm{M}$ and Chamie K: Risk of second primary malignancies among cancer survivors in the United States, 1992 through 2008. Cancer 122(19): 3075-3086, 2016. PMID: 27377470. DOI: 10.1002/cncr.30164

13 Lv M, Zhang X, Shen Y, Wang F, Yang J, Wang B, Chen Z, Li $\mathrm{P}$, Zhang $\mathrm{X}$, Li S and Yang J: Clinical analysis and prognosis of synchronous and metachronous multiple primary malignant tumors. Medicine 96(17): e6799, 2017. PMID: 28445321. DOI: 10.1097/MD.0000000000006799

14 Etiz D, Metcalfe E and Akcay M: Multiple primary malignant neoplasms: A 10-year experience at a single institution from Turkey. J Cancer Res Ther 13(1): 16-20, 2017. PMID: 28508827. DOI: $10.4103 / 0973-1482.183219$

15 Kim JH, Rha SY, Kim C, Kim GM, Yoon SH, Kim KH, Kim MJ, Ahn JB, Chung HC, Roh JK and Kim HS: Clinicopathologic features of metachronous or synchronous gastric cancer patients with three or more primary sites. Cancer Res Treat 42(4): 217224, 2010. PMID: 21253324. DOI: 10.4143/crt.2010.42.4.217

16 Shah BK, Khanal A and Hewett Y: Second primary malignancies in adults with gastric cancer - A US Population-based study. Front Oncol 6(82): 2016. PMID: 27148474. DOI: 10.3389/fonc. 2016.00082

17 El-Serag HB: Epidemiology of viral hepatitis and hepatocellular carcinoma. Gastroenterology 142(6): 1264-1273, 2012. PMID: 22537432. DOI: 10.1053/j.gastro.2011.12.061

18 Keegan THM, Bleyer A, Rosenberg AS, Li Q and Goldfarb M: Second primary malignant neoplasms and survival in adolescent and young adult cancer survivors. JAMA Oncol 3(11): 15541557, 2017. PMID: 28426850. DOI: 10.1001/jamaoncol. 2017.0465
Received October 18, 2019

Revised November 1, 2019

Accepted November 4, 2019 